\title{
The Current Situation and Improvement Strategy of Physical Education in Colleges and Universities
}

\author{
Chengbin Huang \\ Department of Physical Education, Guandzhou Huashang College, Guangzhou 511300, Guangdong Province, China \\ Chengbin Huang(1979), male, from Linwu County of Hunan Province. Bachelor's degree, lecturer. His main research areas \\ are physical education training and campus football.

\begin{abstract}
At present, physical education is listed as the key teaching. This paper introduces the importance of physical education in Colleges and universities, analyzes the current situation of College Physical Education and explores the improvement strategies of College Physical Education at this stage.
\end{abstract}

Key words: College physical education; Physical education teaching; The current teaching situation; Improvement strategy

Publication date: April, 2021; Publication online: 30 April, 2021

*Corresponding author: Chengbin Huang, sjdgg223@163.com

\section{Introduction}

The essence of sports is to strengthen the body and promote the healthy development of body and mind. In order to effectively improve the effectiveness of physical education teaching, it is necessary to strengthen the effective innovation of teaching methods. Under the background of comprehensive quality education, the content of college physical education can not meet the development needs of modern students. Due to a single training method, lack of interest in sports, resulting in the effect of physical education is not ideal. In order to improve the existing problems scientifically, it is necessary to analyze them effectively. In any university, sports is an essential link, the quality of education directly affects the overall level of education and the overall development of students. Physical education can improve students' physical and mental health and improve their physique. In recent years, more and more attention has been paid to the reform of university education. Although the level of university education continues to improve, the quality of physical education can not meet the needs of College Students' physical and mental development. Therefore, key universities must timely analyze sports problems, fully understand the single teaching method, deepen sports reform and optimize teaching methods. Through improving the physical education system, strengthening the construction of teaching staff and seeking the improvement strategies suitable for the development, we can promote the development of the whole university education level. Tian Hongwei ${ }^{[1]}$ pointed out that: In order to arouse students' learning enthusiasm, universities must pay attention to the reform of physical education, better cultivate students' physical exercise habits, and promote students' physical and mental health. After analyzing the universality of college sports at the present stage, this paper puts forward some strategies on how to improve sports. Cheng binpeng ${ }^{[2]}$ studied the current college physical education, analyzed the problems existing in the current college physical education, and put forward the corresponding improvement measures. The action of improving the level of university sports promotes the development of university sports. Cao Xuefeng ${ }^{[3]}$ mainly expounds the importance of college physical education, analyzes the problems of college physical education, and puts forward specific feasible suggestions to promote the development of college physical education.

\section{The importance of physical education to}

\section{university education at present}

\subsection{Improve physical strength}

One of the most basic functions of sports is to improve students' lifestyle and health. In the middle school learning process, students pay more and more attention to their own learning. Although people pay more and more attention to 
core literacy and the combination of work and rest, in fact, students still spend less time on sports. Apart from academic reasons, most students stay up all night and are under great pressure. In this regard, universities should pay attention to it and make corresponding changes. In the process of improvement, specific and effective actions should be made according to regional characteristics. Jogging, marathon and other common sports can improve students' patience and endurance. Weightlifting and other items can train the strength of the area.

\subsection{Promote mental health growth}

The great influence of physical education is to help students reduce pressure and promote mental health. The current social development is getting better and better, at the same time, the ability of young people to resist pressure also has special difficulties. Both students and social groups will face all kinds of pressure. In special education, physical education teachers and schools should develop various subjects according to students' interests and needs. At the same time, they should regard students as the objects of subject education and emphasize their educational atmosphere and fun. Create a positive atmosphere, so that students can experience the charm of the game and get the effect of the game.

\subsection{Achieve the coordinated development of physical and mental health}

Due to too many learning tasks, high learning pressure, short exercise time and poor overall physical quality, most college students have carried out screening tests such as high school entrance examination and college entrance examination. Physical endurance, strength and flexibility are three important parts of fitness. In addition to these three aspects, college students are required to complete comprehensive physical training. For example, running can improve students' endurance, while weightlifting can improve students' strength. Physical education can improve students' mental health. Active sports activities make students get rid of the pressure of study and avoid all kinds of negative effects caused by excessive pressure of study. At the same time, according to more interesting sports content, such as the actual situation of education, teachers make education plans, so that students can actively participate in sports activities.

\subsection{Cultivate sentiment and personality}

University sports activities must carry out a variety of sports activities, the university is a micro society, students can experience their own development in advance in the university environment. Taking part in different sports can make people of different ages actively participate. Physical exercise enables college students to learn from each other's strengths, develop ethics and learn professional knowledge.

\section{Current situation of physical education in}

\section{Colleges and Universities}

\subsection{The quality of teaching is poor and the teaching ideas are solidified}

Although the current high-quality education reform has made great progress, the situation of University shaping education still exists. Teachers only participate in the process of completing teaching tasks, while students only complete tasks so that they can graduate successfully. This kind of education is difficult to ensure the quality of education, long-term development will lead to the bottleneck period of the development of university sports.

\subsection{The teaching method is single and the teaching evaluation system is not perfect}

Teaching method is an important factor to improve the quality of teaching, but the current university sports teaching stage mainly emphasizes the internal self role of teachers and students. It leads to the lack of participation of students, unable to obtain the basic sports knowledge of physical exercise, anxiety about learning, and eventually lead to the weakening of physical education. As education evaluation is the key link of college physical education, it directly affects the smooth progress of college physical education, so it is necessary to take education evaluation as the guidance to quickly achieve the goal of physical education. However, in the current stage of college physical education, physical education teachers do not pay attention to the results of teacher evaluation, and the identity of physical education professor eventually leads to the imbalance of physical education.

\subsection{The attention of physical education is low}

In the actual classroom, educational objectives and related tasks have been standardized, but teachers use fixed methods to improve the efficiency of physical education teaching, and the explanation and demonstration process is strict, lack of practicality and interest. In addition, the physical education classroom often lacks the full supervision of the students' 
training process, which will reduce the learning efficiency and affect the effect of physical exercise. College physical education often regularizes teaching tasks and requires physical education teachers to complete teaching tasks on time. In this case, physical education teachers often strive to complete the educational task on time, in order to save time and energy. Teaching with this attitude should be a strict traditional explanation and demonstration method, which can completely distinguish students from classroom textbooks. In a completely passive learning environment, students will gradually lose their physical education curriculum. In the actual university sports work, most of the physical education teachers show to students, but can't supervise students, leading to low learning efficiency.

\section{Strategies to improve sports at present}

\subsection{Promote the diversity of physical education teaching methods}

Because the simplification of physical education teaching methods is the main reason for the development of physical education in Colleges and universities, therefore, colleges and universities should promote the diversification of physical education teaching methods to promote the progress of physical education teaching reform. First of all, physical education is divided into compulsory subjects and elective subjects. By introducing elective subjects into physical education, students can show their strengths and promote personality development, thus fully stimulating people's enthusiasm for sports. Secondly, it further promotes the richness of sports content. In addition to the traditional track and field sports and ball games, universities should also actively introduce yoga and other new sports, so as to arouse students' interest through the new sports, and effectively improve the attractiveness of physical education. The organic combination of the two promotes the diversification of physical education teaching methods, and ultimately promotes the improvement of college physical education teaching quality.

\subsection{Abandon the traditional education idea and optimize the education system}

The reform and development of physical education in Colleges and universities should further optimize the education system, abandon the traditional education concept, make students become the main body of development, and improve the overall quality of students as the ultimate goal of physical education. Design an education plan that is easy for students to accept. By actively introducing entertainment and cultural functions and maintaining fitness functions, sports standards have been further improved. In addition, teachers should design education system to instill the spirit of students' lifelong movement, actively mobilize students' learning enthusiasm, so that students are not only interested in learning, but also actively participate in their own development. By improving the basic knowledge of physical exercise, in order to improve the students' awareness of physical exercise, we can further improve the physical education level of the University, and effectively improve the education level of the whole school.

\subsection{Strengthen the construction of teachers}

Teachers are the main factor affecting the quality of college physical education. An excellent team of physical education teachers can effectively improve the overall efficiency of college physical education. Therefore, universities should strengthen the construction of teaching staff and promote the improvement of teachers' comprehensive quality, so as to effectively mobilize students' learning enthusiasm and improve their teaching quality. Teachers need to strengthen physical exercise. In learning sports theory, we need to strengthen physical exercise. We must fully master professional sports skills to ensure the correctness of educational skills. Colleges and universities can invite professional athletes to receive education guidance, improve the teaching practice of physical education teachers, improve their professional quality, and provide high-quality professionals for the country.

\subsection{Continuous education evaluation and improvement}

Physical education in Colleges and universities is not perfect. In the long run, to effectively improve the quality of physical education, it is necessary to actively find and improve the existing problems. Therefore, it is necessary to continuously evaluate and improve college physical education. College physical education evaluation is to evaluate the teaching conditions and subject contents of teachers. Through the evaluation results, we can understand the shortcomings of teachers, improve teaching methods and improve the quality of education. The evaluation results will be fed back to the decision-making department of the school, and can also provide reference materials for decision-making. Therefore, 
in terms of continuing education evaluation and improvement, the following actions can be taken, one of which is to assume the role of students and carry out the task of education evaluation. Students can give full play to their role in sports evaluation, and can use students as the goal of sports evaluation. In the evaluation, students' self-evaluation, peer evaluation, group evaluation and teacher evaluation can be combined. These evaluation methods can evaluate the effectiveness of college physical education more objectively and comprehensively, and can provide the basis for improving the level of physical education. The second is to adopt an evaluation method combining teachers' self-evaluation and mutual evaluation. Colleges and universities can consider the actual situation of sports work and carry out regular selfevaluation of physical education teachers to evaluate personal achievements and shortcomings in sports.

\subsection{Actively improve the sports management system}

In college physical education, it is necessary to constantly sum up experience, strengthen the effective improvement of physical education evaluation, fully understand students' mastery of sports, strengthen the control of education situation, and timely feedback the survey results to the school. To provide scientific reference and effectively improve the sports management system. In order to evaluate sports activities through the combination of self-evaluation and mutual evaluation, it is necessary to ensure the fairness and objectivity of the evaluation process. PE teachers must conduct self-evaluation regularly to really understand their own loopholes. We should make a comprehensive evaluation of sports work and improve the timeliness of sports work.

\section{Conclusion}

In recent years, great attention has been paid to the reform of university education. Although the level of university education is constantly improving, the quality of physical education cannot meet the needs of College Students' physical and mental development. Therefore, key universities must timely analyze sports problems, fully understand the single teaching method, deepen sports reform and optimize teaching methods. Through improving the physical education system, strengthening the construction of teaching staff and seeking the improvement strategies suitable for the development, we can promote the development of the whole university education level. This paper briefly introduces the importance of physical education in Colleges and universities, analyzes the current situation of physical education in Colleges and universities, and explores the improvement strategies of physical education in Colleges and universities at this stage.

\section{References}

[1] Tian HW. Problems and improvement strategies of College Physical Education at present [J]. Intelligence, 2019(22): 58 .

[2] Cheng BP. Problems and improvement strategies of College Physical Education Teaching at present [J]. Journal of Jilin Institute of education, 2016, 32(3): 89-91.

[3] Cao XF. Problems and improvement strategies of College Physical Education at present $[\mathrm{J}]$. Neijiang science and technology, 2019, 40(11): 73-74.

[4] Wang WS. Discussion on the Existing Problems and Improvement Strategies of Physical Education in Colleges and Universities at the Present Stage [J]. Intelligence, 2018(14): 139. 